\title{
Stimulation of rhesus monkey sperm capacitation by cyclic nucleotide mediators
}

\author{
D. E. Boatman and B. D. Bavister \\ Wisconsin Regional Primate Research Center, 1223 Capitol Court, Madison, Wisconsin 53715-1299, \\ U.S.A.
}

\begin{abstract}
Summary. Capacitation of rhesus monkey spermatozoa was assessed by monitoring sperm flagellar beat and trajectory changes during incubation in vitro and by determining sperm penetration into rhesus oocytes and hamster zona-free ova. Rhesus sperm capacitation in vitro depended on the addition to the culture medium of the cyclic nucleotide mediators, caffeine and dibutyryl cyclic AMP. Capacitation was correlated with the development of hyperactivated motility. Spermatozoa treated with the cyclic nucleotide mediators, and showing hyperactivated motility, penetrated $57.4 \%$ of all rhesus oocytes and fertilized $88.9 \%$ of mature rhesus oocytes that were morphologically normal. Control spermatozoa did not penetrate any of the eggs. Some sperm penetration into hamster ova occurred but was not statistically significant. These data provide a basis for achieving in-vitro fertilization in the rhesus monkey and information on specific sperm motility characteristics associated with fertilizing ability.
\end{abstract}

\section{Introduction}

The current clinical practices of human in-vitro fertilization followed by embryo transfer are based on data obtained using non-primate models, mostly rodents and the rabbit. Further experimental studies of in-vitro fertilization, embryo transfer, and early preimplantation development that could have more direct application to man would require an animal (a) whose overall reproductive physiology is comparable to that of man and (b) whose social behaviour and mental development are similarly complex. The rhesus monkey meets these criteria and, in addition, has already been studied for its embryology, and post-natal development (Harlow \& Mears, 1979). As part of our programme to develop an in-vitro method for studying primate fertilization and embryogenesis by using the rhesus monkey, we have investigated the conditions required to support sperm penetration of rhesus monkey oocytes in vitro.

For penetration of mammalian egg investments (cumulus oophorus and zona pellucida) spermatozoa must be vigorously motile and have undergone additional changes, termed capacitation, outside the male tract (Yanagimachi, 1981). Rhesus spermatozoa appear to require capacitation in vivo (Marston \& Kelly, 1968). The time-course of sperm capacitation has been correlated with changes in substrate metabolism (Harrison, 1977), altered calcium fluxes, removal of sperm surface components (Yanagimachi, 1981), and/or alterations of lipid domains on the sperm head (Bearer \& Friend, 1982), increases in cyclic nucleotides (Garbers \& Kopf, 1980), and alterations of sperm flagellar beat and swimming trajectory (Johnson, Katz \& Overstreet, 1981).

Changes in hamster sperm flagellar beats and associated swimming trajectories are significant indicators of sperm capacitation and sperm fertilizing ability (Leibfried \& Bavister, 1982). The motility pattern of hamster spermatozoa changes to a distinctive high-amplitude whiplash flagellar 
movement, termed "hyperactivation" (Yanagimachi, 1981), after a period of culture in a defined medium containing sperm motility factors (Leibfried \& Bavister, 1982). Hamster spermatozoa showing hyperactivated motility have been observed within the oviducal ampulla at the time of fertilization and have been observed penetrating the zona pellucida of eggs inseminated in vitro (Yanagimachi, 1981). Similar alterations in motility patterns coincident with fertilizing ability have been described for ampullary rabbit spermatozoa (Cooper, Overstreet \& Katz, 1979), and for bat (Lambert, 1981), mouse (Fraser, 1977), guinea-pig (Yanagimachi, 1972), ram (Cummins, 1982), dog (Mahi \& Yanagimachi, 1976), and marmoset (Moore, 1981) spermatozoa cultured in vitro. Therefore, sperm hyperactivation may be an indicator of capacitation which can be used to assess motile spermatozoa regardless of acrosome size.

The objectives of the present experiments were (a) to find appropriate conditions for achieving in-vitro capacitation of rhesus monkey spermatozoa and (b) to discover whether hyperactivated motility is concomitant with capacitation and fertilizing ability in the rhesus monkey.

\section{Sperm motility assessments}

\section{Materials and Methods}

Semen was collected by electroejaculation from 10 rhesus males of proven fertility (Mastroianni \& Manson, 1963), and the spermatozoa were washed in TALP-Hepes medium and incubated as previously described (Bavister, Boatman, Leibfried, Loose \& Vernon, 1983). Culture dishes containing 5-10 × $10^{6}$ spermatozoa/ml were first observed using a dark-field microscope with a heated stage. Then $7-10 \mu \mathrm{l}$ sperm suspension were placed on siliconized slides and mounted with 20 $\times 20 \mathrm{~mm}$ coverslips for observations with phase-contrast microscopy. Each preparation was allowed to settle on the slide for $30 \mathrm{sec}$ and all observations were completed within the next $30-60$ sec. All manipulations were at $37^{\circ} \mathrm{C}$, unless stated otherwise. Sperm suspensions were examined periodically during incubation for 1-24 h. Assessments were qualitative. Changes in progressive velocity, alterations in sperm flagellar beat (an apparently greater flexion in the region of the sperm neck and midpiece leading to a 'whiplash' beat of the flagellum) with concomitant changes in sperm swimming trajectory (path travelled by the head), and increases in sperm agglutination were noted. A videotape of rhesus spermatozoa was prepared to document representative motility patterns. The pattern(s) of motility of rhesus spermatozoa exhibiting altered swimming trajectories after treatment(s) was compared to that of videotaped hamster spermatozoa showing hyperactivated motility characteristic of capacitated spermatozoa of that species.

\section{Series $I$ and $I I$}

Two series of screening experiments were conducted: Series I tested the effects of serum albumins and periovulatory blood sera, and Series II tested pharmacological effectors of cyclic nucleotide metabolism. The medium used was TALP (Bavister \& Yanagimachi, 1977) containing 3 $\mathrm{mg}$ fraction $\mathrm{V}$ bovine serum albumin/ml (Sigma Chemical Co., St Louis, MO, U.S.A.) except when stated otherwise. In Series I, the incubation media contained 3 or $10 \mathrm{mg} \mathrm{BSA}$ (Fraction V)/ml, 3 or $10 \mathrm{mg}$ fatty acid-free BSA (Miles Laboratories, Elkhart, IN, U.S.A.)/ml, 3 or $10 \mathrm{mg}$ fatty acid-free human serum albumin (HSA, Miles Laboratories) $/ \mathrm{ml}$, or 2 or $10 \%$ hamster or rhesus blood serum plus $3 \mathrm{mg} \mathrm{BSA}$ (Fraction V)/ml. Incubations were carried out for $24 \mathrm{~h}$. In Series II (Table 1), spermatozoa were preincubated for $30 \mathrm{~min}$. Then, caffeine or theophylline $(10 \mu \mathrm{M}-10 \mathrm{mM})$, or dibutyryl cyclic AMP or dibutyryl cyclic GMP (1-5 mM), or caffeine plus dibutyryl cyclic AMP or dibutyryl cyclic GMP were added. An equal volume of $157 \mathrm{mM}-\mathrm{NaCl}$ was added to the controls. Initially using both caffeine and a cyclic nucleotide, the concentration of one was held constant $(0.5-5 \mathrm{~mm})$ while the other was varied over this range. Subsequently, $1 \mathrm{~mm}$-caffeine plus $1 \mathrm{~mm}$ dibutyryl cyclic AMP or dibutyryl cyclic GMP were used. Sperm suspensions were sampled every $30 \mathrm{~min}$ up to $6 \mathrm{~h}$ after addition of cyclic nucleotide mediators, and in some experiments, at periodic intervals up to $24 \mathrm{~h}$. Observations in Series I and Series II were made on a minimum of 6 sperm samples from different males per series. Replication was over days. 
Oocyte penetration and fertilization assays

Two series of penetration and fertilization assays were used to test rhesus sperm capacitation: Series III tested sperm penetration and fertilization in vitro of rhesus monkey oocytes, and Series IV tested rhesus sperm penetration into zona-free hamster ova.

\section{Series III}

Oocytes were obtained from 4 adult rhesus monkeys of reproductive age which had experienced one or more live births. Ovaries were removed from a non-cyclic monkey (replicate 1, Table 2) and from another monkey near midcycle (replicate 2, Table 2). Oocytes were recovered by puncturing follicles that were $0.5-2.0 \mathrm{~mm}$ in diameter. Oocytes were cultured with cumulus and granulosa cells at $37^{\circ} \mathrm{C}$ for $32-35 \mathrm{~h}$ in $100 \mu \mathrm{l}$ drops of medium, under silicone oil, in a $5 \% \mathrm{CO}_{2}$-air atmosphere (see P1. 1, Fig. 1 for immature rhesus oocytes). The culture medium was TALP with $3 \mathrm{mg}$ Fraction V BSA $/ \mathrm{ml}, 0.5 \mathrm{~mm}$-pyruvate, $1.0 \mathrm{~mm}$-glutamine, $0.2 \mathrm{~mm}$-isoleucine, $0.05 \mathrm{~mm}$-methionine, $0.1 \mathrm{~mm}$ phenylalanine, $50 \mu \mathrm{g}$ gentamycin $/ \mathrm{ml}$ (Bavister et al., 1983), and $10 \mu \mathrm{g}$ follicle-stimulating hormone/ml (FSH-P, Burns-Biotech Laboratories Inc., Omaha, NE, U.S.A.). After this maturation incubation, oocytes were graded under the dissecting microscope. Oocytes with a first polar body, expanded cumulus oophorus and normal cytology were classified as potentially fertilizable, Class $\mathrm{F}$ (Bavister et al., 1983; see Pl. 1, Fig. 2 for oocytes with first polar bodies and normal cytology). All other oocytes were classified as potentially penetrable, Class P (Overstreet, Yanagimachi, Katz, Hayashi \& Hanson, 1980). In replicates 3 and 4 (Table 2), oocytes were recovered during laparoscopy by aspiration of follicles from monkeys stimulated with PMSG followed by hCG injected 28-30 h before surgery (Bavister et al., 1983). These were classified immediately. In replicate 4 all of the oocytes were the type (Ia) which we have previously identified as having the greatest potential for developing into 8-16-cell embryos in vitro (Bavister et al., 1983). Within each category, oocytes were randomly assigned to experimental or control groups. Oocytes were placed into $90 \mu \mathrm{l}$ fertilization drops which contained the same medium as the maturation drops but was supplemented with $2 \%$ heated midcycle rhesus blood serum and contained no FSH-P.

Rhesus spermatozoa were obtained from 4 males and washed in TALP-Hepes medium as previously described (Bavister et al., 1983). Spermatozoa were incubated for $4 \mathrm{~h}$ at $20 \times 10^{6}$ spermatozoa/ml in $3 \mathrm{ml}$ TALP medium overlaid with $2 \mathrm{ml}$ silicone oil in an atmosphere of $5 \% \mathrm{CO}_{2}-$ air. Then, $1 \mathrm{mM}$ each of caffeine and dibutyryl cyclic AMP were added to the experimental dishes and equal volumes of $157 \mathrm{~mm}-\mathrm{NaCl}$ were added to the control suspensions. After a further incubation of $1.5 \mathrm{~h}$, aliquants were assessed for hyperactivated sperm motility, Then, the spermatozoa were diluted into the fertilization drops (final concentrations, $2 \times 10^{6}$ spermatozoa/ml, $0 \cdot 1 \mathrm{M}$-caffeine and $0.1 \mathrm{M}$-dibutyryl cyclic AMP).

Class $P$ eggs were fixed after 8-9 h co-incubation with spermatozoa; Class $F$ eggs were rinsed and transferred to fresh medium at $24 \mathrm{~h}$. Class $\mathrm{F}$ eggs matured in vitro were fixed after showing signs of degeneration or $48 \mathrm{~h}$ after the last observed cleavage division (Pl. 1, Fig. 3). Class F eggs matured in vivo (replicate 4 ) which had cleaved to 4 or more cells were not fixed but were transferred to recipients. In this replicate, only abnormal embryos or uncleaved eggs were fixed. At the time of fixation, oocytes were rinsed and pipetted to remove excess granulosa and spermatozoa then fixed in $2 \%$ glutaraldehyde- $2 \%$ formaldehyde in $0 \cdot 12 \mathrm{M}$-phosphate buffer, $\mathrm{pH} 7 \cdot 2$. Oocytes were mounted singly, slightly compressed under a coverslip supported by Vaseline-paraffin wax spots, and examined using interference-contrast optics. Eggs were scored as penetrated if sperm tails were observed deeply embedded in the zona pellucida (Pl. 1, Fig. 4), within the perivitelline space, or lying on the vitelline membrane (Pl. 1, Fig. 5). Confirmation that spermatozoa were embedded in the zona was obtained by rolling the egg so that the spermatozoa were presented equatorially in the egg midway between the slide and coverslip. Cleavage was counted only if cell divisions were regular. For the purpose of data analysis, cleaved eggs were assumed to be penetrated. We have 
previously demonstrated that the experimental conditions used here do not lead to parthenogenetic cleavage of rhesus oocytes (Bavister et al., 1983).

\section{Statistical analysis}

Each replicate of rhesus oocyte penetration and fertilization data was analysed using Fisher's exact test of significance and the significance of combined replicates was calculated according to Fisher (1970).

\section{Series IV}

Female golden hamsters were injected with PMSG on the morning after oestrus. Eggs were recovered from oviducts $16 \mathrm{~h}$ after the ovulatory injection of hCG. The eggs were prepared for the zona-free test as described by Yanagimachi, Yanagimachi \& Rogers (1976). Eggs, 10-15 per drop, were placed into $100 \mu \mathrm{l}$ drops of TALP or BWW medium (Biggers, Whitten \& Whittingham, 1971). Drops also contained $2 \%$ of hamster or rhesus blood serum, or no serum. Rhesus spermatozoa were washed as described by Bavister et al. (1983). Spermatozoa were preincubated at $20-40 \times 10^{6} / \mathrm{ml}$ for 4-24 h in the same medium as the egg drops into which they were to be inseminated (e.g. BWW or TALP, with or without rhesus or hamster serum). The range of sperm concentrations tested in the egg drops was $0.5-10 \times 10^{6}$ spermatozoa $/ \mathrm{ml}$. In some experiments, rhesus spermatozoa were also preincubated as described in Series III. Eggs and spermatozoa were co-cultured for $4-8 \mathrm{~h}$. The eggs were then processed for fixation and mounting and examined by phase-contrast microscopy. Eggs containing sperm heads undergoing various stages of decondensation in the vitellus and which were associated with sperm tails were scored as penetrated.

\section{Results}

\section{Series $I$}

Washed rhesus spermatozoa incubated for up to $24 \mathrm{~h}$ in TALP medium plus $3 \mathrm{mg}$ Fraction $\mathrm{V}$ $\mathrm{BSA} / \mathrm{ml}$ or $3 \mathrm{mg}$ fatty acid-free $\mathrm{BSA} / \mathrm{ml}$ showed a slight decline in progressive velocity and some increase in sperm agglutination over time. Substitution of $3 \mathrm{mg} \mathrm{HSA} / \mathrm{ml}$ or $10 \mathrm{mg}$ Fraction V $\mathrm{BSA} / \mathrm{ml}$ or $10 \mathrm{mg}$ fatty acid-free $\mathrm{BSA} / \mathrm{ml}$ in the medium increased sperm agglutination and decreased progressive velocity. Spermatozoa incubated in TALP ( $3 \mathrm{mg}$ Fraction V BSA/ml)

\section{PLATE 1}

Fig. 1. Immature rhesus follicular oocytes in condensed cumulus oophorus. $\times 52$.

Fig. 2. Follicular rhesus oocytes matured in vitro with first polar body and normal cytology (Class $\mathrm{F}$ oocytes), shown shortly after insemination. $\times 36$.

Fig. 3. Cleaved Class $\mathrm{F}$ rhesus embryo at 6-cell stage, $56 \mathrm{~h}$ after in-vitro insemination which followed $32-36 \mathrm{~h}$ oocyte maturation in vitro. $\times 80$.

Fig. 4. Rhesus spermatozoon penetrating the zona pellucida of a Class $P$ rhesus oocyte. $\times 206$.

Fig. 5. Rhesus spermatozoon lying on the vitelline membrane of a Class P rhesus oocyte. The adjacent round body is probably a germinal vesicle nucleus. $\times 248$.

Fig. 6. Decondensing rhesus spermatozoon in the vitellus of a zona-free hamster ovum. $\times 206$. 
PLATE 1
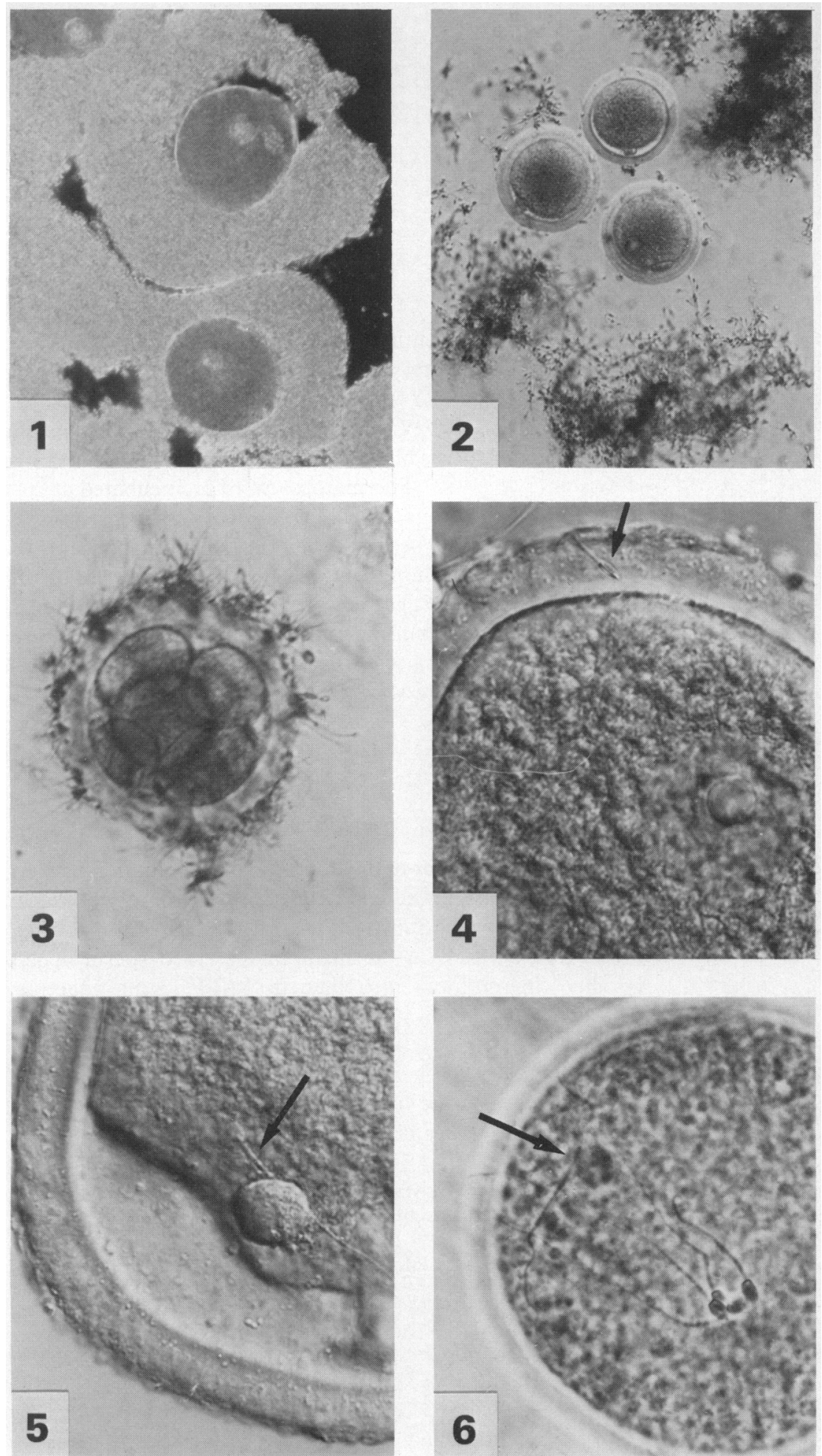

(Facing p. 360) 
supplemented with $2 \%$ hamster or rhesus blood serum had equivalent motility but slightly increased agglutination when compared to those in TALP alone. However, with $10 \%$ hamster or rhesus blood serum, motility was decreased and agglutination increased by as early as $4-6 \mathrm{~h}$. These effects were very pronounced by $24 \mathrm{~h}$. No hyperactivated motility was observed in spermatozoa for any of the incubation procedures.

\section{Series $I I$}

Highly reproducible hyperactivated motility responses with concomitant changes in sperm trajectories were produced in free-swimming (non-agglutinated) spermatozoa that had been treated with 1 mM-caffeine plus 1 mM-dibutyryl cyclic AMP (Text-fig. 1; Table 1). The response was

(a)

(b)

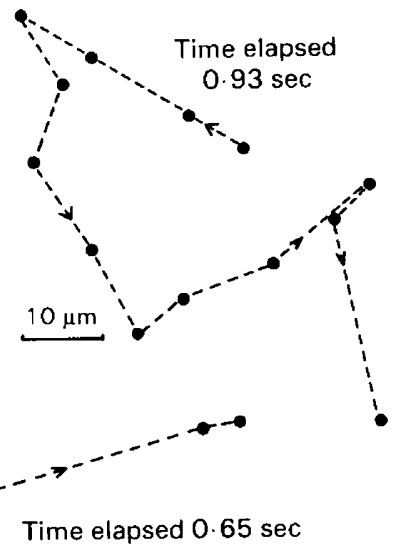

Text-fig. 1. Swimming trajectories of rhesus spermatozoa. Spermatozoa were incubated for $4 \mathrm{~h}$ in TALP medium. Then, $1 \mathrm{mm-caffeine} \mathrm{plus} 1 \mathrm{~mm}$-dibutyryl cyclic AMP was added to (b) and both sperm suspensions ( $a$ and $b$ ) were incubated for an additional $1.5 \mathrm{~h}$. Trajectories were traced from video screen. Dots mark the head/midpiece junction.

Table 1. Motility of rhesus spermatozoa incubated with methylxanthines and cyclic nucleotides and observed during $1.5-6 \mathrm{~h}$ of incubation

\begin{tabular}{|c|c|c|c|}
\hline Additions to medium ${ }^{*}$ & $\begin{array}{c}\text { Change in } \\
\text { progressive } \\
\text { velocity } \dagger\end{array}$ & $\begin{array}{c}\text { Increase in } \\
\text { sperm } \\
\text { agglutination } \dagger\end{array}$ & $\begin{array}{c}\text { Acquisition of } \\
\text { whiplash } \\
\text { (hyperactivated) } \\
\text { motility }\end{array}$ \\
\hline Dibutyryl cyclic AMP 1-5 mM & 0 & 0 & 0 \\
\hline Dibutyryl cyclic GMP $1-5 \mathrm{mM}$ & 0 & 0 & 0 \\
\hline \multicolumn{4}{|l|}{ Caffeine or theophylline } \\
\hline $10 \mu \mathrm{M}-1 \mathrm{mM}$ & $0 /+++\ddagger$ & $+1++$ & 0 \\
\hline $10 \mathrm{~mm}$ & $+1-\S$ & $++t+$ & + \\
\hline Caffeine plus dibutyryl cyclic AMP $1 \mathrm{mM}$ & $+1-\S$ & ++ & +++ \\
\hline Caffeine plus dibutyryl cyclic GMP $1 \mathrm{mM}$ & $0 /+++\ddagger$ & $+1++$ & 0 \\
\hline Control & 0 & 0 & 0 \\
\hline
\end{tabular}

* The medium was TALP with $3 \mathrm{mg}$ Fraction V BSA $/ \mathrm{ml}$. Mediators were added at $30 \mathrm{~min}$. Observations were made at 30 -min intervals.

† Relative to control incubation for $30 \mathrm{~min}$.

$\ddagger$ Spermatozoa with good initial progressive velocity showed little change.

$\S$ Whiplash phase was intermittent but non-progressive. 
maximal by $1.5 \mathrm{~h}$ after treatment. Dibutyryl cyclic GMP could not substitute for dibutyryl cyclic AMP in producing hyperactivated motility. High levels of caffeine or theophylline alone (10 mM), but not dibutyryl cyclic AMP (up to $5 \mathrm{mM}$ ), could produce hyperactivated motility in rhesus spermatozoa. However, high concentrations of methylxanthines significantly reduced the numbers of freely swimming spermatozoa due to sperm agglutination. When videotapes of treated rhesus spermatozoa were compared to those of capacitated hamster spermatozoa, similarities were seen in the hyperactivated motility displayed. The flagellar beat of an individual hyperactivated rhesus spermatozoon assumed an intermittent whiplash pattern. Unlike hamster spermatozoa (which appear to have little or no net progression while hyperactivated), the hyperactivated rhesus spermatozoa continued to progress across the slide, but the trajectories traced by the sperm heads were no longer predominantly linear (Text-fig. 1). The sperm samples used for the observations reported in Table 1 had excellent initial motility ( $\approx 80 \%$ progressive velocity). The cyclic nucleotide mediators had little to no apparent effect on progressive velocity (net unidirectional distance travelled per unit time) of these highly motile spermatozoa when used at concentrations below their threshold for hyperactivated motility. Although forward progressive velocities of control and hyperactivated spermatozoa treated with $1 \mathrm{mM}$-caffeine plus dibutyryl cyclic AMP were clearly different, the actual swimming speeds (total distance travelled by the spermatozoa per unit time) did not appear to differ for the control and hyperactivated spermatozoa (e.g. Text-fig. 1, (a) $=144$ $\mu \mathrm{m} / \mathrm{sec},(\mathrm{b})=155 \mu \mathrm{m} / \mathrm{sec}$ ).

\section{Series $I I I$}

Pre-treatment of rhesus spermatozoa with $1 \mathrm{mM}$-caffeine plus dibutyryl cyclic AMP had significant effects on the penetration and fertilization of rhesus oocytes in vitro (Table 2 ). Of the rhesus oocytes inseminated with pre-treated spermatozoa, $57 \cdot 4 \%$ were penetrated compared to $0 \%$ of the controls (Table 2). Examples of penetrated oocytes are shown in Pl. 1, Figs 3-5. Of the Class F eggs (mature with normal cytology), $89 \%$ cleaved to 2 or more cells compared to $0 \%$ for the

Table 2. Effect of caffeine and dibutyryl cyclic AMP (dbcAMP) on sperm penetration and fertilization of rhesus monkey oocytes from dissected follicles and cultured for $32-35 \mathrm{~h}$ before insemination (replicates 1 and 2) or obtained by follicle aspiration from PMSG/hCG-treated monkeys and cultured for $4 \mathrm{~h}$ before insemination (replicates 3 and 4 )

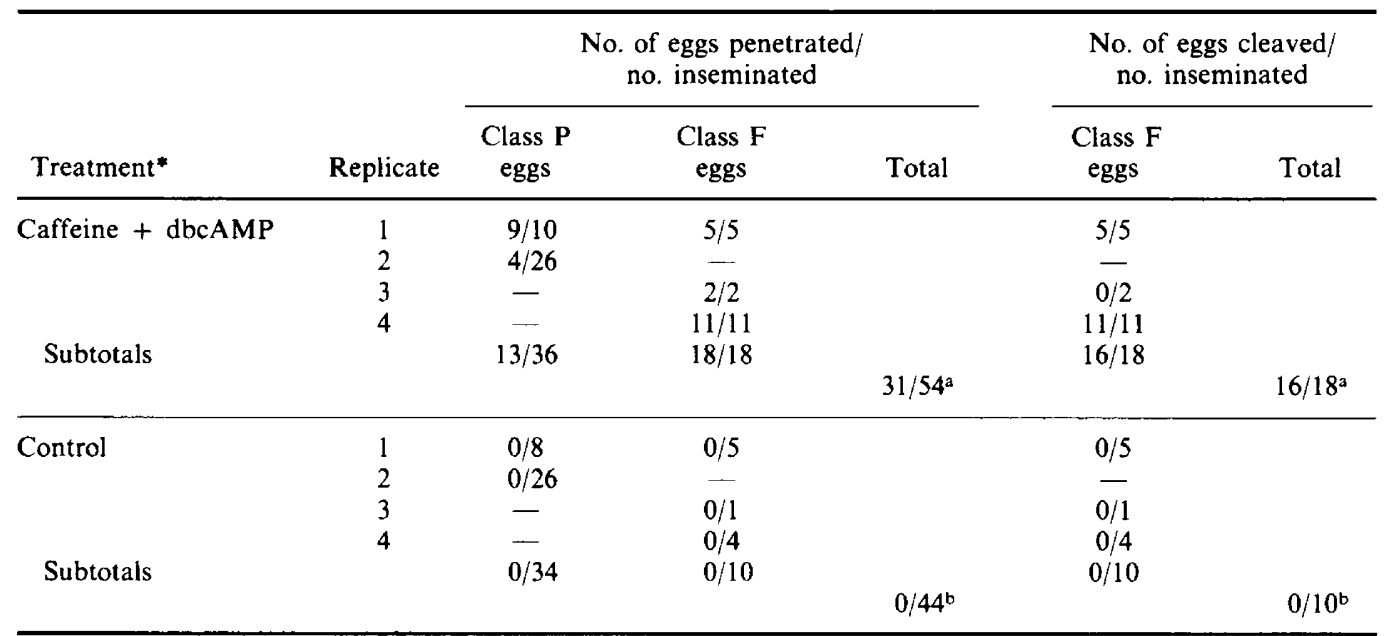

* I mM each during the last $1.5 \mathrm{~h}$ of the 5 -h sperm preincubation and then at $0.1 \mathrm{~mm}$ for $8-9 \mathrm{~h}$ co-incubation with Class $\mathrm{P}$ eggs or for $24 \mathrm{~h}$ co-incubation with Class $\mathrm{F}$ eggs (see 'Materials and Methods' for definitions).

Treatment totals that have different superscripts within the same column are different $(P<0.001)$. 
controls (Table 2; Pl. 1, Fig. 3). No spermatozoa were found in zonae or vitelli of control Class F eggs even though spermatozoa and eggs were co-incubated for $24 \mathrm{~h}$.

Observations on living preparations during the course of experiments were made using both a Wild dark-field dissecting microscope and a Nikon inverted microscope with Nomarski optics. Under these conditions, sperm:egg interactions could easily be seen. Only rhesus spermatozoa preincubated with caffeine plus dibutyryl cyclic AMP bound to zonae almost immediately after egg insemination. Some of these treated spermatozoa showing whiplash-like flagellar movements were observed penetrating the rhesus zonae. By contrast, control spermatozoa were not seen to bind to rhesus zonae although frequent sperm-egg collisions were observed. This difference in zona binding between mediator-treated and non-treated spermatozoa was observed even when sperm suspensions had been preincubated for a longer time $(36 \mathrm{~h})$ before the addition of mediators or sodium chloride, respectively.

\section{Series $I V$}

Regardless of sperm preincubation conditions, only an occasional hamster zona-free ovum was penetrated by rhesus spermatozoa (Pl. 1, Fig. 6). This demonstrated that rhesus spermatozoa can bind to and fuse with hamster egg membranes and that hamster eggs can initiate rhesus sperm decondensation.

\section{Discussion}

In this study, increased cyclic nucleotide levels were implicated in rhesus sperm capacitation and fertilizing ability. In the presence of caffeine plus dibutyryl cyclic AMP, 31/54 of rhesus oocytes were penetrated by spermatozoa compared to $0 / 43$ of the controls (Table 2). Of the 18 experimental Class F oocytes (mature with normal morphology), 16 cleaved to 2 or more cells compared to $0 / 10$ of the equivalent controls. Hyperactivation was induced in rhesus spermatozoa by caffeine plus dibutyryl cyclic AMP but not by caffeine plus dibutyryl cyclic GMP (Table 1). Other incubation conditions which support capacitation in vitro of spermatozoa of different species (e.g. human, hamster: Rogers, 1978) did not elicit hyperactivated motility in rhesus spermatozoa. Development of hyperactivated motility was correlated with rapid binding of rhesus spermatozoa to zonae pellucidae and was exhibited by spermatozoa during penetration of the zonae. Untreated rhesus spermatozoa, regardless of incubation time in TALP, were not found adhering to zonae during detailed microscopic examination.

The rhesus penetration assays included granulosa cells, spermatozoa and eggs. Therefore, it is possible that more than one cell type was affected by the treatment(s) used. Several lines of evidence suggest that the predominant treatment effect(s) which led to increased sperm penetration of eggs occurred directly on the sperm cells. First, only spermatozoa pretreated with caffeine plus dibutyryl cyclic AMP bound to eggs without delay after insemination. Second, the penetration of oocytes did not vary with the culture conditions and preincubation time of the egg/cumulus complexes (Table 2, compare Class F oocytes in replicates 1 and 4). If the effects of caffeine plus dibutyryl cyclic AMP had been mediated through stimulation of granulosa cell secretion(s) (Hillensjö, Magnusson, Svensson \& Thelander, 1981), this would not have been the expected result. Third, oocytes matured in vivo (replicate 4), whose cellular investments were fully expanded (Type Ia: Bavister et al., 1983), were as dependent on caffeine plus dibutyryl cyclic AMP for penetration as were the other types of oocytes (Table 2, compare replicate 4 to all others). This observation is not consistent with the primary treatment effect occurring through stimulation of cumulus oophorus and corona radiata expansion, thereby removing a steric hindrance to sperm penetration. Finally, spermatozoa treated with caffeine plus dibutyryl cyclic AMP developed hyperactivated motility in the absence of egg/cumulus complexes (Table 1). The hyperactivated motility of rhesus spermatozoa was strikingly similar to that displayed by capacitated ampullary spermatozoa of 
rabbits, rams, mice and hamsters (Fraser, 1977; Johnson et al., 1981; Yanagimachi, 1981; Cummins, 1982).

Hyperactivated motility correlated with sperm capacitation has been reported for at least 9 species including two primates, rhesus monkeys (this report) and marmoset monkeys (Moore, 1981). Two possible functions for this type of motility have been suggested: (1) hyperactivated motility may permit a few superior or vanguard spermatozoa to escape the isthmus of the oviduct and to enter the ampulla (Cooper et al., 1979); (2) the vigorous thrusting of the flagellum may mechanically aid sperm passage through the egg investments (Yanagimachi, 1981). While hyperactivated motility has not been unequivocally described for human spermatozoa, there are indications of special motility characteristics associated with their fertilizing ability. These may be similar to those we detected in rhesus spermatozoa. Under conditions of egg penetration, rapid flagellar beats of high amplitude have been measured for human spermatozoa bound to zonae. Movement of these bound spermatozoa was described as a vigorous "thrusting against the zona substance" (Gould et al., 1983). This was similar to our observations on caffeine and dibutyryl cyclic AMP-treated rhesus spermatozoa bound to zonae ('Results', Series III). Caffeine treatment of human spermatozoa in vitro has been shown to increase the numbers of spermatozoa showing irregular swimming trajectories (Gorus, Finsy \& Pipeleers, 1982; Serres, Feneux \& David, 1982). We also detected irregular trajectories in rhesus spermatozoa treated with caffeine plus dibutyryl cyclic AMP (Text-fig. 1b). Human spermatozoa treated with caffeine have been described as showing "an agitated motility characterized by sudden changes in direction" at $2 \mathrm{~h}$ of incubation, a time which corresponded to the onset of enhanced penetration by treated spermatozoa into hamster zona-free ova (Perreault \& Rogers, 1982). We similarly found maximal effects of caffeine plus dibutyryl cyclic AMP on rhesus sperm motility and trajectory changes after $1.5 \mathrm{~h}$ of incubation ('Results' \& Table 1). Rhesus spermatozoa so treated bound to rhesus zonae without delay. Decreased progressive velocity of sperm suspensions has been considered evidence of the deleterious effect of caffeine on human spermatozoa (Harrison et al., 1980). Instead, it may represent an increase in movement parameters (Gorus et al., 1982) underlying the development of irregular swimming trajectories which may be related to hyperactivation and correlated with capacitation.

The physiological mediators of hyperactivated motility in spermatozoa are largely unknown. In hamster spermatozoa, $\beta$-amino acids (taurine and hypotaurine) and catecholamines control this type of motility in vitro and are also the likely mediators in vivo (Leibfried \& Bavister, 1982). In cellular systems which have been characterized, catecholamines act by altering cellular calcium fluxes and/or by increasing intracellular concentrations of cyclic AMP (Rasmussen \& Goodman, 1977). Tash \& Means (1983) have reviewed the molecular mechanisms by which cyclic AMP regulates sperm motility. The synergism of caffeine, classified as a phosphodiesterase inhibitor, and dibutyryl cyclic AMP, a more membrane permeable analogue of cyclic AMP, in producing hyperactivated motility in rhesus spermatozoa (Table 1), clearly implicates increased intracellular cyclic AMP in this sperm behaviour.

Although hyperactivated motility is not equivalent to capacitation per se, the dual location of cyclic AMP-dependent proteins in the flagellum and sperm head (Tash \& Means, 1983) may account for the usually tight coupling observed between hyperactivated motility and capacitation (Johnson et al., 1981). Modifications of the surface membranes of the sperm head occur during capacitation and culminate in a calcium-dependent acrosome reaction (Yanagimachi, 1981). In the present study, rhesus spermatozoa treated with caffeine plus dibutyryl cyclic AMP showed evidence of head-surface modifications: (1) increased sticking to plastic or siliconized glass; (2) increased agglutination; (3) increased binding to zonae pellucidae. These changes in the rhesus spermatozoa may have occurred as a consequence of increased intracellular cyclic AMP and/or by effects of caffeine unrelated to inhibition of phosphodiesterase (Tash \& Means, 1983). One such effect of caffeine could be altered cellular calcium metabolism. Caffeine and other methylxanthines 
induce acrosome reactions in abalone spermatozoa primarily by increasing calcium uptake (Kopf, Lewis \& Vacquier, 1981).

We have observed consistently high penetration of rhesus spermatozoa into zona-intact homologous eggs (Table 2; also Bavister et al., 1983), but little to no penetration of hamster vitelli. This experience was similar to that reported for crab-eating macaques, Macaca fascicularis (Kreitmann, Lynch, Nixon \& Hodgen, 1982). One possible explanation for these observations would be that the macaque zona is both the site and the stimulus for the acrosome reaction of the penetrating spermatozoon, as shown for the mouse (Saling \& Storey, 1979). There are also data which may implicate an effector role for the zona pellucida in normal human sperm penetration. Differences have been shown between capacitation as measured by penetration of homologous zonae or by penetration of hamster vitelli (Gould et al., 1983). Penetration of zona-intact human oocytes was favoured when there was a low percentage of acrosome-reacted spermatozoa in the bulk suspension. Conversely, the penetration of hamster vitelli increased with higher percentages of acrosome reactions in the sperm suspension. Physiologically abnormal spermatozoa could penetrate hamster vitelli but not homologous oocytes. These data together with ours show that caution must be exercised in interpreting results of sperm penetration into hamster zona-free ova. Conditions optimal for penetration of hamster vitelli may not be the most appropriate for penetration of homologous oocytes. As a corollary, failure to penetrate hamster vitelli does not positively identify conditions unsatisfactory for homologous fertilization.

Overall, our experiments have provided a method for capacitating rhesus monkey spermatozoa in vitro. A fuller understanding of motility characteristics specifically related to capacitation should aid in the search for physiological mediators of sperm fertilizing ability in primates and other species. The conditions described here for obtaining capacitation of rhesus spermatozoa have led to the first successful demonstration of fertilization and cleavage in vitro of rhesus oocytes (Bavister $e t$ $a l ., 1983)$. The procedures used to capacitate rhesus spermatozoa thus may have value for both basic and applied research.

We thank Steven Eisele and Michael Hempel for skilled technical assistance and Dr W. Dan Houser and Dr Hideo Uno for providing rhesus ovaries. This work was supported by NIH Grant Nos. HD14765 (to B.D.B.) and RR00167 to the Wisconsin Regional Primate Research Center. This is publication No. 23-028 of the WRPRC.

\section{References}

Bavister, B.D. \& Yanagimachi, R. (1977) The effects of sperm extracts and energy sources on the motility and acrosome reaction of hamster spermatozoa in vitro. Biol. Reprod. 16, 228-237.

Bavister, B.D., Boatman, D.E., Leibfried, L., Loose, M. \& Vernon, M.W. (1983) Fertilization and cleavage of rhesus monkey oocytes in vitro. Biol. Reprod. 28, 983999.

Bearer, E.L. \& Friend, D.S. (1982) Modifications of anionic-lipid domains preceding membrane fusion in guinea pig sperm. J. Cell Biol. 92, 604-615.

Biggers, J.D., Whitten, W.K. \& Whittingham, D.G. (1971) The culture of mouse embryos in vitro. In Methods in Mammalian Embryology, pp. 86-116. Ed. J. C. Daniel. Academic Press, New York.

Cooper, G.W., Overstreet, J.W. \& Katz, D.F. (1979) The motility of rabbit spermatozoa recovered from the female reproductive tract. Gamete Res. 2, 35-42.

Cummins, J.M. (1982) Hyperactivated motility patterns of ram spermatozoa recovered from the oviducts of mated ewes. Gamete Res. 6, 53-63.
Fisher, R.A. (1970) Statistical Methods for Research Workers, pp. 92-101. Oliver and Boyd, Edinburgh.

Fraser, L.R. (1977) Motility patterns in mouse spermatozoa before and after capacitation. J. exp. Zool. 202, $439-444$.

Garbers, D.L. \& Kopf, G.S. (1980) The regulation of spermatozoa by calcium and cyclic nucleotides. In Advances in Cyclic Nucleotide Research, Vol. 13, pp. 251-306. Eds P. Greengard \& G. A. Robinson. Raven Press, New York.

Gorus, T.K., Finsy, R. \& Pipeleers, D.G. (1982) Effect of temperature, nutrients, calcium, and cAMP on motility of human spermatozoa. Am. J. Physiol. 242, C304-311.

Gould, J.E., Overstreet, J.W., Yanagimachi, H., Yanagimachi, R., Katz, D.F. \& Hanson, F.W. (1983) What functions of the sperm cell are measured by in vitro fertilization of zona-free hamster eggs? Fert. Steril. 40, 344-352.

Harlow, H.F. \& Mears, C. (1979) The Human Model: Primate Perspectives. John Wiley \& Sons, New York. 
Harrison, R.A.P. (1977) The metabolism of mammalian spermatozoa. In Frontiers in Reproduction and Fertility Control, Part 2, pp. 379-401. Eds R. O. Greep \& M. A. Koblinsky. MIT, Cambridge.

Harrison, R.F. Sheppard, B.L. \& Kalizer, M. (1980) Observations on the motility, ultrastructure and elemental composition of human spermatozoa incubated with caffeine. II. A time sequence study. Andrologia 12, 434-443.

Hillensjö, L., Magnusson, C., Svensson, U. \& Thelander, H. (1981) Effect of LH and FSH on steroid synthesis by cultured rat cumulus cells. In Dynamics of Ovarian Function, pp. 105-110. Eds N. B. Schwartz \& M. Hunzicker-Dunn. Raven Press, New York.

Johnson, L.L., Katz, D.F. \& Overstreet, J.W. (1981) The movement characteristics of rabbit spermatozoa before and after activation. Gamete Res. 4, 275-282.

Kopf, G.S., Lewis, C.A. \& Vacquier, V.D. (1981) Regulation of abalone sperm cyclic nucleotide (CN) metabolism and the acrosome reaction (AR) by extracellular calcium and methylxanthines (MX). $J$. Cell Biol. 91, 178a.

Kreitmann, O., Lynch, A., Nixon, W.E. \& Hodgen, G.D. (1982) Ovum collection, induced luteal dysfunction, in vitro fertilization, embryo development and low tubal ovum transfer in primates. In In Vitro Fertilization and Embryo Transfer, pp. 303-324. Eds E. S. E. Hafez \& K. Semm. MTP Press, Lancaster.

Lambert, H. (1981) Temperature dependence of capacitation in bat sperm monitored by zona-free hamster ova. Gamete Res. 4, 525-533.

Leibfried, M.L. \& Bavister, B.D. (1982) Effects of epinephrine and hypotaurine on in-vitro fertilization in the golden hamster. J. Reprod. Fert. 66, 87-93.

Mahi, C.A. \& Yanagimachi, R. (1976) Maturation and sperm penetration of canine ovarian oocytes in vitro. J. exp. Zool. 196, 189-196.

Marston, J.H. \& Kelly, W.A. (1968) Time relationships of spermatozoon penetration into the egg of the rhesus monkey. Nature, Lond. 217, 1073-1074.

Mastroianni, L. \& Manson, W.A. (1963) Collection of monkey semen by electroejaculation. Proc. Soc. exp. Biol. Med. 112, 1025-1027.

Moore, H.D.M. (1981) An assessment of the fertilizing ability of spermatozoa in the epididymis of the marmoset monkey (Callithrix jacchus). J. Androl. 4, $321-330$.

Overstreet, J.W., Yanagimachi, R., Katz, D.F., Hayashi, K. \& Hanson, F.W. (1980) Penetration of human spermatozoa into the human zona pellucida and the zona-free hamster egg: a study of fertile donors and infertile patients. Fert. Steril. 33, 534-542.

Perreault, S.D. \& Rogers, B.J. (1982) Relationship between fertilizing ability and cAMP in human spermatozoa. J. Androl. 3, 396-401.

Rasmussen, H. \& Goodman, D.B.P. (1977) Relationships between calcium and cyclic nucleotides in cell activation. Physiol. Rev. 57, 421-508.

Rogers, B. J. (1978) Mammalian sperm capacitation and fertilization in vitro: a critique of methodology. Gamete Res. 1, 165-223.

Saling, P.M. \& Storey, B.T. (1979) Mouse gamete interactions during fertilization in vitro. J. Cell Biol. 83, 544-555.

Serres, C, Feneux, D. \& David, G. (1982) Microcinematographic analysis of the motility of human spermatozoa incubated with caffeine. Andrologia 14, 454- 460 .

Tash, J.S. \& Means, A.R. (1983) Cyclic adenosine $3^{\prime} \cdot 5^{\prime}-$ monophosphate, calcium and protein phosphorylation in flagellar motility. Biol. Reprod. 28, 75-104.

Yanagimachi, R. (1972) Fertilization of guinea pig eggs in vitro. Anat. Rec. 174, 9-20.

Yanagimachi, R. (1981) Mechanisms of fertilization in mammals. In Fertilization and Embryonic Development In Vitro, pp. 81-182. Eds L. Mastroianni \& J. D. Biggers. Plenum Press, New York.

Yanagimachi, R., Yanagimachi, H. \& Rogers, B.J. (1976) The use of zona-free animal ova as a test-system for the assessment of the fertilizing capacity of human spermatozoa. Biol. Reprod. 15, 471-476.

Received 11 July 1983

\section{Note added in proof}

One of the Class F oocytes from replicate 4, Table 2, that was fertilized in vitro with spermatozoa treated with caffeine and dibutyryl cyclic AMP has produced a normal infant after non-surgical transfer to a surrogate rhesus monkey (Bavister, B. D., Boatman, D. E., Collins, K., Dierschke, D. J. \& Eisele, S. G., 1984, Proc. natn. Acad. Sci. U.S.A., in press). 